\title{
The Association between Burnout and Job Satisfaction among Dental Undergraduates and Faculty
}

\author{
Shatha Subhi ALHarthi ${ }^{1}$ BDS, MSc \\ Monika Maya Wahi ${ }^{2} \quad$ MPH, CPH
}

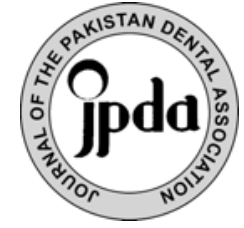

\begin{abstract}
:
Background: This study aimed to determine levels of burnout and job satisfaction in dental students and faculty, and to examine any association between them.

Methodology: A total of 31 students and 17 faculty at a Saudi Arabian dental college completed an online survey including demographics, the Maslach Burnout Inventory to measure burnout, and the Dentist Satisfaction Survey to measure job satisfaction. Descriptive statistics and correlations were calculated.

Results: Both students and faculty were moderately to highly burned out, with students significantly more burned out than faculty. Faculty were neutral on job satisfaction, but students were dissatisfied with level of personal time. In all participants, burnout was statistically significantly negatively inversely correlated with job satisfaction.

Conclusions: Burnout and job satisfaction were found to be strongly inversely correlated, and this may lead to staff turnover among faculty, as well as stress-related health and academic problems among students.

Practical Implications. This workplace should explore limiting clinical and academic obligations for its staff and students to allow them more personal time in hopes of reducing burnout levels and increasing job satisfaction.
\end{abstract}

KEYWORDS: Burnout, Emotional Fatigue, Management, Medical Staff

HOW TO CITE: ALHarthi SS, Wahi MM. The Association between Burnout and Job Satisfaction among Dental Undergraduates and Faculty. J Pak Dent Assoc 2017; 26(2): 46-53

Received: 22 December 2016, Accepted: 24 March 2017

\section{INTRODUCTION}

$\mathrm{B}$ urnout describes a process beginning with high and sustained levels of stress resulting in feelings of irritability, fatigue, detachment and cynicism¹. Burnout in healthcare providers has been implicated as a cause of many negative outcomes, including patient safety compromises ${ }^{1}$, provider health problems ${ }^{2}$, and provider turnover" "Burnout is associated with a lower effectiveness at work ...", reduced "... job satisfaction ... “ and "... commitment to the job or the organization". It has also been found to be associated with intention to leave one's job ${ }^{2}$. Therefore, burnout in healthcare providers can be a concern for healthcare management, because the providers

1. Assistant Professor of Periodontology, Department of Periodontology, College of Dentistry, Princess Nourah Bint Abdulrahman University, Riyadh, Kingdom of Saudi Arabia

2. Lecturer, General Education Department, Laboure College, Milton, Massachusetts, and Vasanta Health Science, Boston, Massachusetts, United States of America

Corresponding author: "Ms. Monika M. Wahi"

< mwahi@vasantahealth.com > who suffer burnout may try to leave their positions due to low job satisfaction.

Burnout has been documented among dentists. Robert Baran $^{3}$ did a survey of 202 practicing dentists in the United States (US) and used the Maslach Burnout Inventory (MBIHSS), which measures three subscales of burnout ${ }^{4}$. Baran found that on average, dentists were moderately burned out on two of the three subscales ${ }^{3,5}$. Hoseini and colleagues ${ }^{6}$ more recently used the MBI-HSS to measure burnout in 38 dentists from Birjand, Iran, and found the "frequency of exhaustion, intense depersonalization, and intense feeling of being unsuccessful was $21.1 \%, 81.6 \%$, and $100 \%$, respectively". Al-Mobeeriek and Al-Mobeeriek ${ }^{7}$ used the Arabic version of the MBI-HSS to measure burnout in 370 academic and non-academic dentists in the Kingdom of Saudi Arabia (KSA), and found that over a fourth of general dentists were suffering from high levels of emotional exhaustion.

Burnout has been seen in dental trainees as well. A systematic review of studies of stress in dental students found that they experience considerable amounts of stress, 
mainly due to the demanding nature of the training, and the results of the studies suggest that there are adverse effects of elevated stress on students' health and well-being ${ }^{8}$. Studies of dental students at various stages of training and in various settings have found that they are burned out or experiencing an elevated level of stress. A 2014 study of second-year, fourth-year, and fifth-year dental students in Spain found that $43.1 \%$ of second-year students were burned out and $50.9 \%$ of fourth-year students were burned out, but only $25.6 \%$ of fifth-year students are burned out ${ }^{9}$. A German study also found that dental students were on average moderately burned out ${ }^{10}$.

As described before, burnout reduces a healthcare provider's commitment to his or her organization, and can increase his or her intention to leave the job ${ }^{2}$. In a study of job satisfaction among Korean dentists, researchers found that mean overall job satisfaction was only 3.2 out of 5 , and patient relations, perception of income, personal time, staff, and specialty training, which can influence burnout, were important work environment factors influencing job satisfaction ${ }^{11}$. A similar result was found in a study of Egyptian dentists, where mean job satisfaction was 3.24 out of $5^{12}$, and in Saudi dental assistants, where the mean job satisfaction was 3.86 out of $5.00^{13}$. In both studies, perception of income and patient relations were major factors influencing job satisfaction ${ }^{12,13}$.

Although dental trainees have not begun their careers as professional independent dentists, they generally complete their training in the same environment with professional faculty, and take on independent responsibility for a patient load. For this reason, dental trainees could be surveyed for their "job satisfaction", as they are completing the same tasks as career dentists, although under very intense supervision. Evidence to support the concept of undergraduate or graduate level dentists actually having a "job" and therefore being able to have "job satisfaction" could be seen by reading into the results of a study on postgraduate dentists who essentially were experiencing the same high level of stress as career dentists ${ }^{14}$.

Setting can be an important influence on job satisfaction. Specifically, public sector dentists have been studied to better understand why they may choose to leave the public sector. In an Australian study, "gradual frustration because of poor remuneration and lack of professional autonomy", which are components of job satisfaction, were significant reasons that dentists were leaving the public sector ${ }^{15}$. In a study of academic staff at a Saudi university, only $63.7 \%$ said they were satisfied with their jobs ${ }^{16}$.

It is likely that dental students and faculty who are burned out also have a low job satisfaction. However, no studies could be identified that attempted to correlate levels of burnout in dental students and faculty with levels of job satisfaction. Baran's study of dentists in the US measured both burnout and job satisfaction, but did not attempt to relate the two, instead relating these measures to measures of personality type. Therefore, how burnout and job satisfaction are related in dental students and faculty is unknown.

At Princess Nourah Bint Abdulrahman University College of Dentistry PNU-COD, pre-doctoral students ("undergraduates") are considered fourth-year and fifth-year students. These students are all from Saudi Arabia, with between 30 and 40 students in each class. There are approximately 40 full-time faculty members who have clinical responsibilities from Saudi Arabia and other countries; these members fall into the following hierarchical position categories: Lecturer, Assistant Professor, Associate Professor, and Professor. General Practitioners (GPs) are also on the workforce, but they do not have any teaching responsibilities, and only have clinical responsibilities.

Although studies of dental students and faculty have been undertaken to research burnout, studies generally do not include measures of burnout in both faculty and dental students, so it is not possible to compare levels between faculty and students. Further, no studies to date have examined levels of burnout and job satisfaction both dental students and faculty, and their potential associations. The aim of the present study is to measure the level of burnout and job satisfaction experienced by dental students and faculty at PNU-COD and to examine if there is an association between burnout and job satisfaction.

\section{METHODS}

\section{Participants and Setting}

The survey was conducted among faculty and students at PNU-COD. For the faculty, to qualify for the survey, they needed to be working full-time at PNU-COD, hold clinical responsibilities at PNU-COD, be age 18 or over, and understand written English, as the survey was in English. Students qualified if they were age 18 or over, understood written English, and were enrolled at PNU-COD as a fourthor fifth-year student at the time of the survey. This study was reviewed by the Ethics Research Board (ERB) at Princess Nourah Bint Abdulrahman University College of Dentistry. The ERB found that due to the anonymity of the survey, the study was exempt from oversight by the ERB. Because it was exempt from oversight, the ERB could not grant approval nor require informed consent. Due to the anonymity of those completing the survey, although consent language was present on the first page of the survey, no 
Table 1. MBI-HSS Scoring Rules

\begin{tabular}{|c|c|c|c|}
\hline MBI Subscale & Low-Level Burnout & Moderate Burnout & High-Level Burnout \\
\hline Emotional Exhaustion (EE) & 17 or less & 18 through 29 & 30 or greater \\
\hline Depersonalization (DP) & 5 or less & 6 through 11 & 12 or greater \\
\hline Personal Achievement (PA) & 40 or greater & 34 through 39 & 33 or less \\
\hline
\end{tabular}

documentation of informed consent was obtained. The research has been conducted in full accordance with the World Medical Association Declaration of Helsinki.

\section{Development and Administration of Survey}

Two different versions of the surveys were developed: one for faculty, and one for students. Both included the 22question MBI-HSS ${ }^{17}$, where respondents rate statements as to how often the respondent feels the statement is true: Never, a few times per year, once a month, a few times per month, once a week, a few times per week, or every day. These entries are associated with numbers, and subscales are scored through sums. The MBI-HSS produces three subscales: Emotional exhaustion (EE), depersonalization (DP), and personal achievement (PA). The MBI-HSS is considered high-quality and is the main instrument currently used to measure burnout ${ }^{1,6,10,18}$. The scoring rules for these subscales are presented in Table 1. Please note that higher EE and DP scores indicate higher burnout, and lower PA score indicates higher burnout.

The survey also included the questions from the 29question Dentist Satisfaction Survey $(\mathrm{DSS})^{19}$, which has been found to be a high-quality instrument and has been used in studies cited in the introduction to measure job satisfaction in dentists ${ }^{12,13}$. Respondents are asked to rate statements on the scale of strongly disagree, disagree, neutral, agree, or strongly agree. This survey produces an overall score, as well as these subscales: Overall job satisfaction $(\mathrm{O})$, perception of income (PI), personal time (PET), professional time (PRT), staff (S), patient relations (PR), delivery of care (DC). Subscales are scored by taking a mean. Table 2 lists the scoring rules for the DSS; the higher the score, the more satisfied the respondent. Please note that the PI subscale was not included in the student survey as the students were not making any income.

In addition, the student survey asked for age, status (fourth- or fifth-year), and typical work hours (4 hours or less or more than four hours). The faculty survey asked for age, department (Preventive, Clinical, Basic or Other), faculty level (Lecturer, Assistant Professor, Associate Professor, and Professor), highest level of education (Bachelor's degree, Master's degree, Doctoral degree or other), and typical work hours (4 hours or less, 4 to 8 hours, and more than 8 hours).

The survey was administered online through SurveyMonkey $^{20}$. A link was sent to each student and faculty

Table 2. DSS Scoring Rules

\begin{tabular}{|c|c|c|c|}
\hline DSS-29 Subscale & Dissatisfied & Neutral & Satisfied \\
\hline All questions (overall score) & \multirow{8}{*}{$\begin{array}{c}\text { Mean of } 1.0-2.5 \text { on indicated } \\
\text { questions }\end{array}$} & \multirow{8}{*}{$\begin{array}{c}\text { Mean of }>2.5-<3.5 \text { on indicated } \\
\text { questions }\end{array}$} & \multirow{8}{*}{$\begin{array}{c}\text { Mean of } 3.5-5.0 \text { on indicated } \\
\text { questions }\end{array}$} \\
\hline Overall Job Satisfaction (O) & & & \\
\hline Perception of Income (PI)* & & & \\
\hline Personal Time (PET) & & & \\
\hline Professional Time (PRT) & & & \\
\hline Staff (S) & & & \\
\hline Patient Relations (PR) & & & \\
\hline Delivery of Care (DC) & & & \\
\hline
\end{tabular}

*Not measured in students. 
e-mail address for them to complete the survey. Several reminder e-mails were sent. Data collection took place November 22 through December 31, 2016.

\section{Data Analysis Approach}

Using $\mathrm{R}^{21}$, faculty and student scores were developed for the subscales of the MBI-HSS and the DSS. Using the scoring rules in Tables $\mathbf{1}$ and $\mathbf{2}$, mean subscales were classified as low, moderate, or high for the MBI-HSS subscales, and dissatisfied, neutral, and satisfied for the DSS subscales. To determine if faculty scores on subscales were statistically significantly different from student scores on

Table 3. Faculty and Student Demographics

\begin{tabular}{|c|c|c|c|}
\hline & $\begin{array}{c}\text { Faculty } \\
\text { n, } \%\end{array}$ & & $\begin{array}{c}\text { Students } \\
\text { n, } \%\end{array}$ \\
\hline Total Surveys & $17,100 \%$ & & $31,100 \%$ \\
\hline \multicolumn{4}{|l|}{ Age Group } \\
\hline$<18$ & $0,0 \%$ & & $0,0 \%$ \\
\hline $18-30$ & $3,18 \%$ & & $31,100 \%$ \\
\hline $31-40$ & $8,47 \%$ & & $0,0 \%$ \\
\hline $41-50$ & $3,18 \%$ & & $0,0 \%$ \\
\hline $51-60$ & $2,12 \%$ & & $0,0 \%$ \\
\hline $61+$ & $1,6 \%$ & & $0,0 \%$ \\
\hline \multicolumn{4}{|l|}{ Department* } \\
\hline Preventive & $1,6 \%$ & & \\
\hline Clinical & $7,41 \%$ & & \\
\hline Basic & $6,35 \%$ & & \\
\hline Other & $3,18 \%$ & & \\
\hline Faculty Level & & Student Status & \\
\hline Lecturer & $4,24 \%$ & Fourth-year & $21,68 \%$ \\
\hline Assistant Professor & $8,47 \%$ & Fifth-year & $10,32 \%$ \\
\hline Associate Professor & $2,12 \%$ & & \\
\hline Professor & $3,18 \%$ & & \\
\hline \multicolumn{4}{|c|}{ Faculty Highest Level of Education* } \\
\hline Bachelor's Degree & $0,0 \%$ & & \\
\hline Master's Degree & $5,29 \%$ & & \\
\hline Doctoral Degree & $12,71 \%$ & & \\
\hline Other & $0,0 \%$ & & \\
\hline Faculty Typical Work Hours & & Student Typical Work Hours & \\
\hline 4 hours or less & $0,0 \%$ & 4 hours or less & $1,3 \%$ \\
\hline 4 to 8 hours & $9,53 \%$ & More than 4 hours & $30,97 \%$ \\
\hline More than 8 hours & $8,47 \%$ & & \\
\hline
\end{tabular}

*Not applicable for students. 
Table 4. MBI-HSS and DSS Results

\begin{tabular}{|c|c|c|c|c|c|}
\hline MBI-HSS Results & Student (mean) & Student Level & Faculty (mean) & Faculty Level & p-value ** \\
\hline Emotional Exhaustion & 28.45 & Moderate & 19.24 & Moderate & 0.003 \\
\hline Depersonalization & 17.48 & High & 11.82 & High & 0.026 \\
\hline Personal Achievement & 33.45 & Moderate & 38.24 & Moderate & 0.015 \\
\hline \multicolumn{6}{|l|}{ DSS Results } \\
\hline Overall & 3.03 & Neutral & 3.35 & Neutral & 0.035 \\
\hline Overall Job Satisfaction & 3.24 & Neutral & 3.63 & Satisfied & 0.767 \\
\hline Personal Income* & NA & NA & 3.18 & Neutral & NA \\
\hline Personal Time & 1.89 & Dissatisfied & 2.51 & Neutral & 0.039 \\
\hline Professional Time & 2.70 & Neutral & 2.80 & Neutral & 0.247 \\
\hline Staff & 2.67 & Neutral & 3.14 & Neutral & 0.036 \\
\hline Patient Relations & 3.78 & Satisfied & 4.16 & Satisfied & 0.036 \\
\hline Delivery of Care & 3.67 & Satisfied & 3.69 & Satisfied & 0.920 \\
\hline
\end{tabular}

*Personal Income questions were not asked of students.

**p-value from independent t-tests between students and faculty.

subscales, independent t-tests were used, and alpha set at 0.05. To assess the correlation between MBI-HSS subscales and DSS subscales, Pearson correlation coefficients were developed.

\section{RESULTS}

The survey was sent to 65 students and 37 full-time faculty. A total of 31 student and 17 faculty surveys were available for analysis (response rate $48 \%$ and $49 \%$, respectively).

Table 3 presents the demographics for the faculty and students who completed the surveys. All of the students were between 18 and 30 years old, while faculty covered all age ranges. The largest representation of faculty was from the clinical department $(n=7,41 \%)$ and the second largest was from the basic department $(n=6,35 \%)$. Most of the faculty who completed the surveys were Assistant Professors $(n=8,47 \%)$, and most of the students who completed the survey were fourth-years $(n=21,68 \%)$. Almost three-fourths of the faculty completing the survey had a doctoral degree $(\mathrm{n}=12,71 \%)$, and slightly less than half reported working more than 8 hours per day $(n=8,47 \%)$. For students, $97 \%$ $(n=31)$ said they work more than 4 hours per day.
Table 4 presents the results for both students and faculty for subscales of both the MBI-HSS and the DSS. In terms of burnout, both faculty and students were on average moderately burned out on the EE and PA subscales, and highly burned out on the DP subscale. Even so, students were on the higher end of the same scale as faculty, such that their raw scores were statistically significantly higher for $\mathrm{EE}$, and DP, and statistically significantly lower for PA ( $\mathrm{p}=$ $0.0030,0.0261$, and 0.0150 respectively).

In terms of DSS overall score and subscales, students measured as satisfied on only two scales, PR and DC. With $\mathrm{PR}$, they were still significantly less satisfied compared to faculty $(p=0.0356)$, but their high satisfaction with DC was not statistically significantly different from faculty $(\mathrm{p}=$ 0.9202). With respect to $\mathrm{S}$, both students and faculty were neutral, but faculty were statistically significantly more satisfied with respect to raw score $(p=0.0360)$. Students and faculty were equally neutral with respect to PRT ( $\mathrm{p}=$ 0.2472), but with respect to PET, students were dissatisfied, while faculty were significantly higher, scoring in the neural category $(p=0.0392)$. Faculty were neutral with respect to $\mathrm{PI}$, and for $\mathrm{O}$, faculty were classified as satisfied on average, while students were only neutral; however, this difference was not statistically significant $(\mathrm{p}=0.7667)$. For the overall DSS score, both students and faculty were neutral on average, but faculty scored statistically significantly higher 
$(p=0.0345)$. PI was not measured in students, but in faculty, it was found to be neutral on average.

Although faculty overall were not as burned out as students, and had higher satisfaction than students, a clear association was seen between higher burnout and lower job satisfaction, especially when correlating the overall DSS score with the EE subscale from the MBI-HSS, as seen in the scatter plot shown in Fig. (1). There was a strong, inverse correlation of $-0.73(p<0.0001)$ between the DSS and EE scores in both faculty and students.

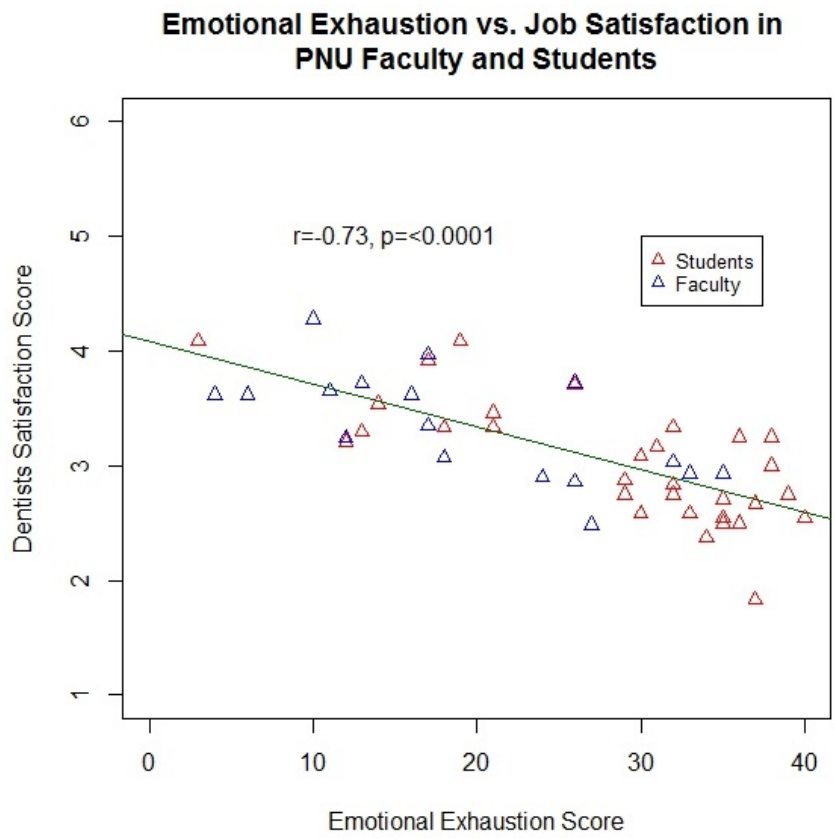

Fig. (1). Heat Map Showing Correlations Between DSS and MBIHSS Subscales in Faculty and Students. Note: EE = emotional exhaustion, DP = depersonalization, $\mathrm{PA}=$ personal achievement, DSS $=$ overall DSS score, $\mathrm{O}=$ overall job satisfaction, $\mathrm{PET}=$ personal time, $\mathrm{PRT}=$ professional time, $\mathrm{S}=$ staff, $\mathrm{PR}=$ patient relations, $\mathrm{DC}=$ delivery of care.

Fig. (2) shows a heat map of all the subscales and their correlations. The top two rows represent the EE and DP subscales from the MBI-HSS. The red coloring across these rows indicates strong inverse correlations with the DSS subscales, indicating a strong inverse correlation between burnout and job satisfaction. All the DSS scales were moderately to highly positively correlated with each other, as shown by the blue color on the figure.

\section{DISCUSSION}

The results showed that the both the faculty and students at PNU-COD appeared to be moderately to highly burned out, and to have neutral to low job satisfaction. Though both faculty and students appeared to be experiencing burnout and lack of job satisfaction, students were significantly more burned out and significantly less satisfied than the faculty. In addition, there was also a strong inverse correlation between burnout levels and job satisfaction in both the students and the faculty.

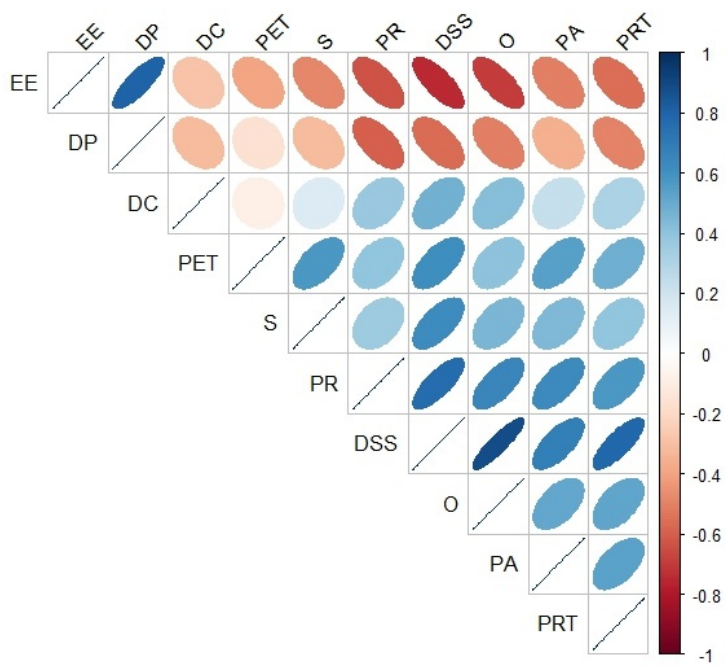

Fig. (2). Scatter Plot of Overall Dentist Satisfaction Score and Emotional Exhaustion Subscale in Faculty and Students.

The findings about burnout and job satisfaction in the faculty measured in the study are relatively consistent in with the literature. They echoed the findings from the survey of KSA academic and non-academic dentists by AlMobeeriek and Al-Mobeeriek ${ }^{7}$ in terms of burnout, and also mirrored findings of low job satisfaction in academic dentists in KSA from another study ${ }^{16}$.

Our study also showed, however, that these items were inversely correlated, suggesting that burnout could be leading to a high turnover rate in staff. As PNU-COD is a young college, founded in 2011, it is still growing, and along the way has experienced intermittent staff shortages. PNUCOD has unique hiring challenges. It is located in Riyadh, Saudi Arabia, and consistent with local norms, it maintains an all-female staff serving only female clientele. Finding workers who are female, qualified, and able to commit time to this profession can be challenging, although the female educated healthcare workforce in Saudi Arabia is continuing to expand. These challenges could elevate workplace stress, which could backfire by increasing burnout, leading staff to quit and escalating turnover rates, thus exacerbating the problem. 
We also found a high level of burnout in students in our study, which was consistent with the findings from the studies in Spain and Germany described earlier ${ }^{9,10}$. Our finding of neutral to low job satisfaction in students, however, was novel. As with the burnout, scores on most of the job satisfaction subscales were statistically significantly lower for students compared to faculty, and they were especially dissatisfied with the amount of personal time they had. While burnout and low job satisfaction in faculty might lead to turnover, there are likely worse consequences for this combination in students. In the Spanish study, the prevalence of suicidal ideation jumped almost statistically significantly between third-year and fourth-year dental students $^{9}$. It is especially alarming to see these results in an environment that is geared toward developing the student intellectually, not breaking her down. Unlike the faculty member, who can quit one job and get another, the student taking leave from a dental studies program due invokes consequences that are much more serious and can forever impact the trajectory of the student's careers.

In reflection on the results from this study, PNU-COD will be encouraged to explore limiting the clinical or didactic obligations for both students and faculty in an effort to expand their amount of personal time, as students specifically expressed dissatisfaction with the amount of personal time available. Allowing faculty and students to have more personal time will allow them to engage in nonwork activities which can hopefully alleviate their feelings of burnout. If policy changes are implemented, after some time, the PNU-COD could survey their faculty and students again to determine if the intervention has had a positive impact.

\section{CONCLUSION}

In conclusion, our study found that burnout was moderate to high and job satisfaction neutral to low in both faculty and dental students at PNU-COD. Even so, students experienced significantly higher burnout and lower job satisfaction, and were specifically dissatisfied with their amount of personal time. Burnout and job satisfaction were found to be strongly inversely correlated, and this may lead to staff turnover among faculty, as well as stress-related health and academic problems among students. PNU-COD should explore limiting clinical and academic obligations for its staff and students to allow them more personal time in hopes this intervention will help reduce burnout levels and increase job satisfaction. After implementing this intervention, the faculty and students could be surveyed again to assess the impact of the increase in personal time on burnout and job satisfaction.

\section{ACKNOWLEDGEMENT}

The authors would like to acknowledge the staff of the Deanship of Scientific Research at Princess Nourah Bint Abdulrahman University for their help with survey administration.

\section{AUTHORS CONTRIBUTION}

We attest that both authors made substantial contribution to the conception and design of the study. The original study was Dr. AlHarthi's idea, and she contacted Ms. Wahi to assist with study design, data collection plans, and statistical analysis. Dr. ALHarthi collected the data, and worked with Ms. Wahi to analyze and interpret it. Together, Dr. ALHarthi and Ms. Wahi drafted the paper, and both gave final approval on the version being submitted.

\section{CONFLICT OF INTEREST}

The authors declare no conflicts of interest. This study did not receive financial support. Study data are deidentified and can be accessed by contacting the corresponding author. Both authors confirm the integrity and accuracy of data analysis.

\section{Research was conducted at:}

College of Dentistry, Princess Nourah Bint Abdulrahman University, Riyadh, Kingdom of Saudi Arabia

Abstract poster presentation at the American Dental Education Association meeting, May 8-9, 2017, London, England.

\section{REFERENCES}

1. Profit J, Sharek PJ, Amspoker AB, Kowalkowski MA, Nisbet CC, Thomas EJ, et al. Burnout in the NICU setting and its relation to safety culture. BMJ Qual Saf. 2014 Oct;2310:806-13.

2. Embriaco N, Papazian L, Kentish-Barnes N, Pochard F, Azoulay E. Burnout syndrome among critical care healthcare workers. Curr Opin Crit Care. 2007 Oct;135:482-8.

3. Baran RB. Myers Briggs Type Indicator, burnout, and satisfaction in Illinois dentists. Gen Dent. 2005 Jun;533:228-234; quiz 235.

4. Maslach C, Jackson SE, Leiter MP. Maslach Burnout Inventory Manual. 3rd edition. Menlo Park, CA: Consulting Psychologists Pr; 1996. 
5. Maslach Burnout Inventory Scoring Rules [Internet]. Association des Medecins Veterinaires; [cited 2015 May 26]. Available from: http://opencourses.emu.edu.tr/pluginfile.php/9241/mod_ resource/content/1/Burnout-self-test.pdf

6. Hoseini MH, Sharifzadeh G, Khazaie T. Occupational burnout in Birjand dentists. J Dent Med. 2011 Apr 15;242:113-20.

7. Al-Mobeeriek HF, Al-Mobeeriek AF. Burnout among dental academics and non-academics in Riyadh and Eastern Province, Saudi Arabia. J Pak Dent Assoc. 2011;4:199-205.

8. Elani HW, Allison PJ, Kumar RA, Mancini L, Lambrou A, Bedos C. A systematic review of stress in dental students. J Dent Educ. 2014 Feb;782:226-42.

9. Galán F, Ríos-Santos JV, Polo J, Rios-Carrasco B, Bullón P. Burnout, depression and suicidal ideation in dental students. Med Oral Patol Oral Cir Bucal. 2014 May;193:e206-11.

10. Prinz P, Hertrich K, Hirschfelder U, de Zwaan M. Burnout, depression and depersonalisation Psychological factors and coping strategies in dental and medical students. GMS Z Für Med Ausbild [Internet]. 2012 Feb 15 [cited 2016 Jan 13];291. Available from: http:/www.ncbi.nlm.nih.gov/pmc/articles/PMC3296106 /

11. Jeong S-H, Chung J-K, Choi Y-H, Sohn W, Song K-B. Factors related to job satisfaction among South Korean dentists. Community Dent Oral Epidemiol. 2006 Dec;346:460-6.

12. Fahim AE. Predictors of job satisfaction among practicing dentists at hospitals in Suez Canal Area, Egypt. Int J Occup Med Environ Health. 2013 Mar;261:49-57.

13. AL Jazairy YH, Halawany HS, AL Hussainan N, AL Maflehi N, Abraham NB, Jacob V. Factors affecting job satisfaction and their correlation with educational standards among dental assistants. Ind Health. 2014 Jul;524:324-33.

14. Divaris K, Polychronopoulou A, Taoufik K, Katsaros C, Eliades T. Stress and burnout in postgraduate dental education. Eur J Dent Educ Off J Assoc Dent Educ Eur. 2012 Feb;161:35-42.

15. Hopcraft MS, Milford E, Yapp K, Lim Y, Tan V, Goh $\mathrm{L}$, et al. Factors associated with the recruitment and retention of dentists in the public sector. J Public Health Dent. 2010;702:131-9.

16. Al-Rubaish AM, Rahim SIA, Abumadini MS, Wosornu L. Job satisfaction among the academic staff of a Saudi university: An evaluative study. J Fam Community Med. 2009;163:97-103.

17. Maslach C, Jackson SE. The measurement of experienced burnout. J Organ Behav. 1981 Apr 1;22:99-113.

18. Baran E, Thompson A, Chuang H, Tai S, Wang W, Tao L, et al. Faculty development and diffusion of innovations: Technology mentoring cases from the field. In: Proceedings of the Society for Information Technology \& Teacher Education International Conference [Internet]. Nashville, TN; 2011 [cited 2014 Jun 2]. p. 1771-5. Available from: http://site.aace.org/

19. Shugars DA, Hays RD, DiMatteo MR, Cretin S. Development of an instrument to measure job satisfaction among dentists. Med Care. 1991 Aug;298:728-44.

20. SurveyMonkey. Create surveys, get answers [Internet]. 2015. Available from: https://www.surveymonkey.com/

21. The R Core Team. R: A language and environment for statistical computing. [Internet]. Vienna, Austria; Available from: http:/www.R-project.org/ 